\title{
Effect of a model-based educational program for mothers, on home-related injury prevention among under-five-year children in rural Twiserkan, Iran
}

\author{
Maryam Afshari ${ }^{1}$, Abbas Moghimbeigi ${ }^{2,3}$, Seyed Mohammad Mahdi Hazavehei ${ }^{1,4}$, \\ Forouzan Rezapur-Shahkolai ${ }^{1,5 *}$ \\ ${ }^{1}$ Department of Public Health, School of Public Health, ${ }^{2}$ Department of Biostatistics, School of Public Health, ${ }^{3}$ Modeling \\ of Noncommunicable Diseases Research Center, ${ }^{4}$ Research Center for Health Sciences, and ${ }^{5}$ Social Determinants of Health \\ Research Center, Hamadan University of Medical Sciences, Hamadan, Iran. \\ E- mail: Forouzan.rezapour@gmail.com
}

Received: 26th February 2017, Revised: 29th April 2017, Accepted: 19th May 2017

SUMMARY: Afshari M, Moghimbeigi A, Hazavehei SMM, Rezapur-Shahkolai F. Effect of a model-based educational program for mothers, on home-related injury prevention among under-five-year children in rural Twiserkan, Iran. Turk J Pediatr 2017; 59: 648-656.

Children under 5 years of age are most vulnerable in terms of home-related injuries. As a majority of these injuries are predictable and preventable, it is important to design preventive intervention programs that can be utilized as models of health education.

The aim of this study was to determine the effect of an educational program, using the PRECEDE model, for rural mothers, on home-related injury prevention among under-five-year old children.

This quasi-experimental study was conducted on 72 mothers, with at least one under-five-year old child, in the rural areas of Twiserkan (Toyserkan) County in Iran. The intervention and control groups (36 participants in each), were interviewed in pre/post-test study by trained interviewers, using the questionnaire. The intervention group participated in four educational sessions. The questionnaire included the questions on demographic information, mothers' beliefs and caring in relation to child-injury prevention, based on the PRECEDE model and focusing on predisposing factors (knowledge and attitudes), enabling factors; reinforcing factors; and mothers' preventive behaviors.

According to the results of the study, the mean scores of predisposing factors (knowledge), enabling and reinforcing factors and also mothers' behaviors on injury prevention, did not have significant differences between two groups before intervention, whereas they had significant differences after intervention.

This study showed that the educational program, using the PRECEDE model, can be effective on promoting knowledge and performances of mothers in relation to home-related injury prevention among their under-five-year old children.

Key words: child injury, child safety promotion, health education, rural areas, children less than five years old.

Injuries are one of the important causes of mortality and morbidity worldwide. ${ }^{1}$ Injuries as an important health problem affect socioeconomic situations of people negatively, particularly in low and middle-income countries. ${ }^{2}$ According to the report of World Health Organization (WHO) in 2008, injuries are the leading cause of burden of diseases worldwide each year and are responsible for the deaths of 950,000 people in the population under 19 years old. ${ }^{3}$

Injuries are also one of the major causes of death and disability in children. ${ }^{4}$ About 875,000 
children die annually from injuries which make $40 \%$ of all deaths among children in low and middle income countries. ${ }^{5}$ Children under 5 years old are the most vulnerable group to home-related injuries, and burns, poisoning, falls and strike have been reported to be the four main causes of injury among them. ${ }^{6}$ In Iran, the number of deaths among children aged $<5$ years has reduced from 56 per 1000 to 34 per 1000 over recent decades. However, the number of deaths due to injuries has remained constant, and accounts for $6 \%$ of all deaths in this age group; this is higher than the global average. ${ }^{7}$ A study of Poorolajal et al. ${ }^{8}$ showed that the most frequent injuries among children less than 5 years in Hamadan, the capital city of Hamadan province of Iran, were home-related injuries. Effective injury prevention relation actions require the identification of vulnerable groups and specific areas which the maximum benefits can be reached if targeted preventing interventions, healthcare provision and related researches have been done among them. ${ }^{9}$

The researchers regard mothers with children under 5 years as an appropriate group for implementing educational programs among them, because of their role as the key person for caring for the members of the family. ${ }^{10}$ Since education is one of the main pillars of health care, it is necessary to pay more attention to planning educational program, especially based on educational models and theories. ${ }^{11,12}$ Health education with various methods is a good way for motivating and modifying inappropriate performance because health education is the science and art of leading people to pay attention to a learning process, to create desirable behavior in order to achieve health. ${ }^{13}$ Selecting the model of health education is the first step in the designing process of an educational program ${ }^{11,12}$, the PRECEDE (Predisposing, Reinforcing, \& Enabling Constructs in Educational/ Ecological Diagnosis \& Evaluation) Model was introduced by Lawrence Green to understand the behavior problems and thereafter used in designing, planning and evaluation of health education programs. It provides a framework for educational programs and in this framework the associated factors which needs to be determined for more effective change, including behavioral changes, are identified. Among these factors, the education-related factors consisted of predisposing factors (knowledge and attitudes), enabling factors and reinforcing factors. ${ }^{14-16}$ Utilizing the PRECEDE model as an intervention framework for improving healthy behavior has been approved in other studies that have used this model on some health issues. ${ }^{17-20}$

The aim of this study is to determine the effectiveness of educational programs using the PRECEDE model, for rural mothers in Twiserkan (Toyserkan) County, regarding the prevention of home-related injuries among children less than 5 years old.

\section{Material and Methods}

\section{Settings}

This study was a quasi-experimental intervention study which was conducted in 2014 on 72 mothers with at least one child under 5 years who were living in catchment areas of four rural health houses in Twiserkan County, located in west Iran. This study was designed, based on results of the descriptive-analytical study, which was on associated factors with home-related injuries among children in this setting and had been already done by the same research team of the current study. ${ }^{21}$

\section{Sample}

According to results of the above-mentioned study ${ }^{21}$, among the health houses which had the population with the highest frequency of home-related injuries among rural under-5year old children, the current interventional study was done. Therefore, the population in the catchment areas of two health houses was selected as the intervention group and the population in catchment areas of two other health houses was selected as the control group. It is noteworthy that to prevent the contamination of data, the intervention and control groups were in catchment areas of different health houses and villages. The participants were the mothers who had at least one under-five-year old child and were selected through randomly sampling method (36 in intervention group and 36 in the control group).

\section{Intervention}

Regarding the calculated sample size (72 participants, totally) among health-related 
Table I. Demographic Characteristics of the Participants in the Intervention and Control Group $(n=36)$.

\begin{tabular}{|c|c|c|c|}
\hline Characteristics & $\begin{array}{l}\text { Intervention group } \\
\text { Number (\%) }\end{array}$ & $\begin{array}{l}\text { Control group } \\
\text { Number (\%) }\end{array}$ & P-value \\
\hline \multicolumn{4}{|l|}{ Household members number } \\
\hline 3 & $15(42 \%)$ & $19(53 \%)$ & \multirow{4}{*}{0.090} \\
\hline 4 & $10(28 \%)$ & $14(39 \%)$ & \\
\hline 5 & $10(28 \%)$ & $2(6 \%)$ & \\
\hline$\geq 6$ & $1(2 \%)$ & $1(2 \%)$ & \\
\hline \multicolumn{4}{|l|}{ Mothers' age group (in years) } \\
\hline $15-24$ & $12(33.5 \%)$ & $14(39 \%)$ & \multirow{5}{*}{0.269} \\
\hline $25-30$ & $9(25 \%)$ & $12(33.5 \%)$ & \\
\hline $31-34$ & $9(25 \%)$ & $7(19.5 \%)$ & \\
\hline $35-39$ & $4(10.5 \%)$ & $3(8 \%)$ & \\
\hline $40-44$ & $2(6 \%)$ & $0(0 \%)$ & \\
\hline \multicolumn{4}{|l|}{ Fathers' age group (in years) } \\
\hline $15-24$ & $3(8.30 \%)$ & $1(3 \%)$ & \multirow{6}{*}{0.620} \\
\hline $25-29$ & $8(22.2 \%)$ & $12(33 \%)$ & \\
\hline $30-34$ & $12(33 \%)$ & $12(33 \%)$ & \\
\hline $35-39$ & $8(22.2 \%)$ & $8(22 \%)$ & \\
\hline $40-44$ & $3(8.30 \%)$ & $2(6 \%)$ & \\
\hline$\geq 45$ & $2(6 \%)$ & $1(3 \%)$ & \\
\hline \multicolumn{4}{|l|}{ Mothers' educational level } \\
\hline No schooling & $1(3 \%)$ & $1(3 \%)$ & \multirow{5}{*}{0.178} \\
\hline Primary school & $16(44 \%)$ & $23(64 \%)$ & \\
\hline Middle school (grade 6-8) & $10(28 \%)$ & $9(24 \%)$ & \\
\hline High school \& Diploma (grade 9-12) & $8(22 \%)$ & $1(3 \%)$ & \\
\hline University & $1(3 \%)$ & $2(6 \%)$ & \\
\hline \multicolumn{4}{|l|}{ Fathers' educational level } \\
\hline No schooling & $1(3 \%)$ & $0(0 \%)$ & \multirow{5}{*}{0.507} \\
\hline Primary school & $11(31 \%)$ & $7(19 \%)$ & \\
\hline Middle school (grade 6-8) & $14(39 \%)$ & $15(42 \%)$ & \\
\hline High school \& Diploma (grade 9-12) & $9(24 \%)$ & $12(33 \%)$ & \\
\hline University & $1(3 \%)$ & $2(6 \%)$ & \\
\hline \multicolumn{4}{|l|}{ Mothers' jobs } \\
\hline Housewife & $34(94.5 \%)$ & $35(97 \%)$ & \multirow[t]{2}{*}{0.998} \\
\hline Government employed & $2(5.5 \%)$ & $1(3 \%)$ & \\
\hline \multicolumn{4}{|l|}{ Fathers' jobs } \\
\hline Laborer & $22(61 \%)$ & $19(53 \%)$ & \multirow{4}{*}{0.048} \\
\hline Farmer \& dairy & $2(5.5 \%)$ & $9(25 \%)$ & \\
\hline Other self employed & $11(30.5 \%)$ & $6(16.5 \%)$ & \\
\hline Government employed & $1(3 \%)$ & $2(5.5 \%)$ & \\
\hline \multicolumn{4}{|l|}{ Caregiver in the absence of mother } \\
\hline Grandmother & $22(61 \%)$ & $13(36 \%)$ & \multirow{4}{*}{0.116} \\
\hline Father & $8(22 \%)$ & $17(47.5 \%)$ & \\
\hline relatives & $3(8.5 \%)$ & $4(11 \%)$ & \\
\hline Older siblings & $3(8.5 \%)$ & $2(5.5 \%)$ & \\
\hline
\end{tabular}


records of mothers of children under five years old in four selected health houses in four villages, 18 cases were randomly selected from each health house considering inclusion criteria. Participants gave written informed consent and were enrolled in the research project voluntarily. In this study, the intervention group received training about the prevention of home-related injuries for children based on PRECEDE model and control group received no training during the study. Before training sessions, for both intervention and control group, the pre-test questionnaires had been filled out by interviewers and through interviews with mothers. In order to prepare the educational material, a training manual was designed in line with the study aim and objectives and PRECEDE Model constructs. The training manual, as a booklet, was completed and finalized by utilizing scientific resources in health education and promotion and also scientific resources of safety promotion and injury prevention. ${ }^{3,22}$ When designing the content of the booklet, the results of a study by Rezapur et al. ${ }^{21}$, which was on factors associated with injuries in the home, based on the PRECEDE model, and the results of the pre-test phase of the current study were used. After designing the booklet, it was given to the selected mothers, before starting data collection, and in addition to filling them filling it out their opinions about difficult and incomprehensible parts was sought, and the necessary changes were applied. Thereafter, training was presented for the intervention group during the four sessions of two weeks and each for 1 hour, using various teaching methods such as lectures, group discussion and question and answer with instructional booklets (along with a meeting of reminding, a month after the fourth session). And finally, two months after the intervention, we performed an evaluation through interviews with mothers in both groups.

\section{Data collection instruments}

Data collection instrument was a questionnaire in three parts; the first part had the demographic and background questions, including 19 questions. The second part had questions about injured children, and history of homerelated injuries. The questionnaire included 23 questions in this section. This section of the questionnaire was a description and epidemiology of the injury and the questions of which were designed using valid and standard sources of injury related studies. ${ }^{3,22}$ In this study, the definition of home-related injury was considered according to the Ministry of Health. Ministry of Health has defined the "home-related injuries" as burns, falls, cuts, animal or insect attack, drowning, suffocation, electric shock, poisoning, and inanimate mechanical which were occurred at home. ${ }^{21}$ Each injury event was recorded in this study, if the participant reported injury occurrence during past two months, both in pre-test and post-test interviews. The pre-test interviews were done before starting intervention and the post-test interviews were done two months after complementing the intervention period.

The third section consisted of questions in relation to PRECEDE model constructs, including construct of knowledge with 14 multiple-choice questions and a score of between zero and 14. A higher score indicates more awareness about the injury. Construct of attitude had 15 questions with a Likert scale of five options (very much agree, agree, no opinion, disagree, totally disagree), and scores were between 15 and 75. A higher score indicates a favorable attitude about the injury. A number of five questions were designed for the construct of enabling factors associated with access to educational and other resources for the prevention of injury among children (which was scored zero and one) and the availability of care centers measured as zero and one. A number of three questions were provided for the construct of reinforcing factors to encourage family, friends, doctors, and health workers in the field of injury, determined to be zero and one. The construct of preventive behaviors with 30 questions of two items (yes/ no) was related to the maternal function and safety measures taken by the mother and other family members in the house to prevent injury, which was completed by self-reporting through the interviews. Grading for preventive behaviors was between zero and 30, and those who had earned a higher score indicated better performance.

\section{Pilot testing of questionnaire}

To assess the validity of the questionnaire, health education and promotion and safety 
Table II. Mechanisms of Occurred Home-Related Injuries between Intervention and Control Groups Before and After the Intervention.

\begin{tabular}{llll}
\hline \multirow{2}{*}{ Mechanisms of injuries } & $\begin{array}{l}\text { Intervention group } \\
\text { Number (\%) }\end{array}$ & $\begin{array}{l}\text { Control group } \\
\text { Number (\%) }\end{array}$ \\
\hline \multirow{2}{*}{ No injury } & Before intervention & $30(83.5)$ & $30(83.5)$ \\
\multirow{3}{*}{ Fall } & After intervention & $34(94)$ & $28(78)$ \\
& Before intervention & $3(8.25)$ & $2(5.25)$ \\
\multirow{3}{*}{ Burn } & After intervention & $1(3)$ & $3(8)$ \\
\multirow{3}{*}{ Poisoning } & Before intervention & $3(8.25)$ & $2(5.25)$ \\
& After intervention & $1(3)$ & $4(11)$ \\
Stab/cut & Before intervention & 0 & $1(3)$ \\
& After intervention & 0 & 0 \\
& Before intervention & 0 & $1(3)$ \\
& After intervention & 0 & $1(3)$ \\
\hline
\end{tabular}

promotion professionals were referred to and their corrective feedback was applied in the questionnaire. Also, all questions were read for the 10 mothers and their understanding and the difficulty level of questions were reviewed and the proposed amendments were applied. To measure the reliability of the questionnaire in this study, Cronbach's alpha coefficient was used. For that, the prepared questionnaire was completed in a pilot interviewing by 30 mothers of children who had been identified to be injured at the health houses in Twiserkan County. Finally, the alpha coefficient was measured and the results were recorded. The alpha coefficient for the variables of knowledge, attitudes, enabling factors, reinforcing factors and preventive behaviors were 76.0, 73.0, 80.0, 87.0 and 76.0 , respectively.

\section{Response rates}

Participation rate of mothers in the study was $100 \%$.

\section{Data collection}

As the assessment of educational program impact took place two months after the intervention, to compare the number of injuries, the cases of injury were considered two months before and two months after the intervention.

In order to comply with ethical issues, instruction booklets were provided free for mothers. Also, one training session and the educational materials were presented to the control group, after completing the intervention program for the intervention group and doing post-test study in both groups.

\section{Data analysis}

The collected data were analyzed using SPSS16 software at the significance level of $5 \%$. In addition to descriptive statistics, the analytical statistics, including chi-square test, t-test, paired t-test and fisher's exact test, were used in current study. The study was ethically approved by Ethics Committee of Hamadan University of Medical Sciences.

\section{Results}

In this study, there was no child without a mother and a father in the house and the care of children at home was up to mothers (100\%).

Demographic characteristics are shown in Table I. According to this table there was no significant difference between the intervention and control groups except for fathers' job $(\mathrm{P}=0.048)$.

Table II shows that the frequencies of the reported home-related injuries, before and after training, were six and two, respectively, in the intervention group and were six and eight, respectively, in the control group. Fisher's exact test indicated that home-related injuries occurred among children in both groups had no significant difference before and after the intervention.

Table III shows that before training there were no significant differences between the mean scores of the predisposing factor (knowledge), enabling factors, reinforcing factors and 
Table III. Comparison the Mean Scores of the PRECEDE Constructs between the Intervention and Control Groups Before and After the Intervention

\begin{tabular}{|c|c|c|c|c|c|}
\hline \multirow[t]{2}{*}{ Constructs } & \multicolumn{2}{|c|}{ Intervention group } & \multicolumn{2}{|c|}{ Control group } & \multirow[t]{2}{*}{ T-test** } \\
\hline & Mean & SD & Mean & SD & \\
\hline \multicolumn{6}{|c|}{ Predisposing factor (knowledge) } \\
\hline Before intervention & 10.000 & 2.438 & 9.470 & 3.256 & 0.649 \\
\hline After intervention & 12.670 & 0.986 & 9.750 & 1.664 & 0.000 \\
\hline Paired t-test* & 0.000 & & 0.439 & & \\
\hline \multicolumn{6}{|c|}{ Predisposing factor (attitude) } \\
\hline Before intervention & 67.060 & 5.767 & 61.750 & 6.349 & 0.010 \\
\hline After intervention & 72.310 & 3.124 & 65.420 & 5.299 & 0.000 \\
\hline Paired t-test & 0.000 & & 0.040 & & \\
\hline \multicolumn{6}{|l|}{ Enabling factors } \\
\hline Before intervention & 3.310 & 1.939 & 3.720 & 1.256 & 0.103 \\
\hline After intervention & 4.780 & 0.637 & 4.220 & 0.321 & 0.000 \\
\hline Paired t-test & 0.025 & & 0.283 & & \\
\hline \multicolumn{6}{|l|}{ Reinforcing factors } \\
\hline Before intervention & 1.810 & 1.327 & 2.310 & 0.980 & 0.909 \\
\hline After intervention & 3.000 & 0.000 & 2.330 & 1.069 & 0.000 \\
\hline Paired t-test & 0.000 & & 0.073 & & \\
\hline \multicolumn{6}{|l|}{ preventive behaviors } \\
\hline Before intervention & 22.310 & 4.302 & 23.810 & 5.350 & 0.392 \\
\hline After intervention & 29.170 & 0.775 & 22.810 & 4.452 & 0.000 \\
\hline Paired t-test & 0.000 & & 0.194 & & \\
\hline
\end{tabular}

Paired t-test $*=\mathrm{P}$-value

T-test $* *=$ P-value

preventive behaviors between intervention and control groups $(\mathrm{p}>0.05)$. However, after training there was an increase in mean scores of above-mentioned factors in the intervention group with a significant difference between the two groups $(\mathrm{p}<0.05)$. Although the mean score of predisposing factor (attitude) of mothers of two groups on prevention of injury both in before and after the intervention had a significant difference $(\mathrm{p}=0.010)$, but the difference after the intervention was stronger $(\mathrm{p}=0.001)$.

\section{Discussion}

The results of this study showed that the mean scores of mothers' attitudes on prevention of injury between the intervention and control groups were significantly different, before and after the intervention, but the difference after the intervention had a stronger relationship. Average scores of predisposing factor (knowledge), enabling factors, reinforcing factors and preventive behaviors of mothers in relation to prevention of injury in the two groups had no significant differences before intervention, whereas they were statistically significant after the intervention. The mean score of knowledge in the intervention group was statistically significant after the intervention. The results of this study were comparable with the findings of Sanainasab et al. ${ }^{18}$ about the impact of PRECEDE-based training in the field of injury prevention and safety promoting behaviors of workers. Our results are in consistence with those of Altender and colleagues ${ }^{23}$ who studied on utilization of the PRECEDE model and reported the effect of education on students ' awareness about AIDS, and Chiang and colleagues' 24 study who showed awareness as a part of the predisposing factors for asthma management behaviors of parents. The increased awareness of the participants in the current study, demonstrates the effectiveness of interventions based on the PRECEDE model 
to maintain and promote knowledge of mothers regarding prevention of injury. Before the intervention, the mean score of attitude both in two groups had significant differences, but after the intervention, the correlation was stronger. The results in this study were consistent with the findings of Mashreky and colleagues 25 about the attitudes of rural people regarding childhood burns and their prevention. Also, our findings were consistent with those of Hossaini and colleagues ${ }^{19}$ who studied the effects of occupational stress management training. In the current study, before the intervention, the mean scores of attitudes were high in both groups. We believe it is due to the high ratio of positive belief to the importance of this issue among participants including both groups. The mean scores of attitudes in the two groups had increased, two months after the intervention. In the intervention group, it could be due to the impact of the intervention, but in control group this may be due to the sensitivity of mothers after giving informed consent and being interviewed to complete questionnaire about the related issues. The mean scores of enabling factors in the intervention group had increased after the intervention. This increase was statistically significant. The results in this regard were comparable with findings of Chiang and colleagues ${ }^{24}$ about the impact of education based on the PRECEDE model on children's self-management of Asthma. Mothers were sensitive about the importance of home-related injury prevention and used the educational resources in this regard. However, before intervention, the participants in the intervention group have reported that the role of the medical and health staff was lower than that of television and radio to educate them in the field of injury prevention and safety promotion among children. This may be because these staff members are not sensitive enough to injury prevention field and do not have appropriate and adequate training and learning for mothers. In the control group, the first teaching resource which was mentioned by participants was group educational classes. It can be due to the province's health center plans, recently, on preventable death in children, including injury deaths. Abdalla's study ${ }^{26}$ on investigating the prevalence, causes and prevention of injuries among children also focused on the above mentioned issue. Morrongiello `s ${ }^{27}$ study investigating factors affecting the risk of injury among children is inconsistent with our study. In that study, mothers did not consider education as a necessary issue for safety at home and believed it was related to parenting practices. In this study, mothers said that they had taken their injured children to health and/or treatment centers-particularly health houses. That is because a health house is the most accessible place to go for rural mothers in villages. Overall, based on studies, there is a necessity to have a comprehensive and specific training program to improve children's safety in the country and it needs to pay more attention to this important issue among the scientific community and related people in the health system. The mean score of reinforcing factors in the intervention group has increased after the intervention which was significant, statistically. The results in this study were consistent with Salinero-Fort et al's ${ }^{28}$ findings on the use of the PRECEDE model to control of HbAlc, blood pressure, lipids, and body mass index in patients. Studies examining deaths from injuries, found that physicians, health educators and policy makers have an important role in preventing injuries. ${ }^{20,29,30}$

In the current study before education, in the intervention group and in the control group, reinforcing factors, such as health and medical staff were not focused on by participants. This could be due to the poor sensitivity of these people to the training programs in relation to injury prevention and safety promotion. The mean score of preventive behaviors in the intervention group had increased after the intervention. This increase was statistically significant. Our results are consistent with those of Rodolfo et al. ${ }^{31}$ study about the behavior of Brazilian mothers in relation to precautions in the home and Jetten et al. ' $\mathrm{s}^{32}$ study on the evaluation of burns prevention program for children in India, also they are consistent with findings of Rezapur et al. ' $\mathrm{s}^{21}$ study on factors associated with injuries in the home, based on the PRECEDE model. The reason of increase is attributed to the effectiveness of the intervention based on the PRECEDE model on the preservation and promotion of mothers' behaviors for injury prevention. 
The main limitation of this study was its self-reporting nature. To decrease the effect of this limitation, mothers were encouraged to cooperate and give correct information by explaining the importance and purpose of the study. Lack of modern educational media in the class and in the health house was another limitation. Using the facilities in place to fit the needs of learners with educational content including booklets and methods of group discussion and question $\&$ answer would have solved some of the problems. Another problem we encountered was that mothers continued to care for their children during the meetings which could create some disturbances. Mothers were asked to leave their children at home with a caregiver to make better use of the educational classes. Additionally, the number of participants was small and their educational level was low.

But the most important constraint was related to the short interval between the intervention and the final evaluation. Of course, to generalize using the model which was used in this study, it should be tested in different populations and also the long-term effect also needs to be evaluated.

The key benefit of this study was mothers' participation in the project which was $100 \%$. It seems that the high level of interest in participating in the study is because of mothers ' interest in the children safe-caring related issues considering the importance of homerelated injuries. Another advantage of this study was the presenting context-relevant educational program in a rural environment, considering cultural, social, economic situation of the mothers. Regarding research findings, television, radio, and educational classes which were reported as teaching resources in case of injury prevention and safety promotion, seem to have beneficial use in this area. It is suggested that educational units are empowered in health houses to hold educational systematic and continuing classes using the results of this study to enhance the awareness level and skills of mothers in relation to injury preventive behaviors.

Consequently, the relevant authorities of the health and safety promotion need to pay more attention to prevent injuries among children and to social and economic factors in order to design effective preventive intervention programs in order to reduce the incidence of home-related injuries and their consequences on families and community. As the significant changes in levels of related factors including predisposing factors (knowledge and attitudes), enabling factors, reinforcing factors and preventive behaviors, among participants in the intervention group have been shown in current study, it can be concluded that home-related injuries among children may be preventable through training mothers to care for them in a safer manner. Developing and implementing the educational program based on the PRECEDE model, can be beneficial.

\section{Acknowledgements}

This study is part of the thesis which was approved and financially supported by Deputy of Research and Technology of Hamadan University of Medical Sciences (reference number: 9111033960).

\section{REFERENCES}

1. Lozano R, Naghavi M, Foreman K, et al. Global and regional mortality 235 causes of death for 20 age groups in 1990 and 2010: a systematic analysis for the Global Burden of Disease Study 2010. Lancet 2012; 380: 2095-2128.

2. Juillard C, Labinjo M, Kobusingye O, Hyderr AA. Socioeconomic impact of road traffic injuries in West Africa: exploratory data from Nigeria. Inj Prev 2010, 16: 389-392.

3. Peden M, Oyegbite K, Ozaane-Smith J. World report on child injury prevention, Tech Rep Unicef and WHO, 2008.

4. Theurer WM, Bhavsar AK. Prevention of unintentional childhood injury. Am Fam Physician 2013; 87: 502-509.

5. World Health Organization. Injury. 2012. www.who. int/topics/injuries/en.

6. World Health Organization. World Health Statistics. Geneva: WHO. 2010.

7. WHO, Geneva. 2012. Available at: http://apps.who.int/ iris/bitstream/ 10665/70889/1/WHO_IER_HSI_12.1_ eng.pdf (Accessed 15 March 2013).

8. Poorolajal J, Cheraghi P, Hazavehei SM et al. Factors associated with mothers' beliefs and practices concerning injury prevention in under-five-year children, based on health belief model. J Res Health Sci 2012; 13: 63-68.

9. World Health Organization and UNICEF. World report on child injury prevention. Geneva. 2008.

10. Cheraghi P, Poorolajal J, Hazavehi SM, RezapurShahkolai F. Effect of educating mothers on injury prevention among children aged $<5$ years using the Health Belief Model: a randomized controlled trial. Public Health 2014; 128: 825-830. 
11. Glanz K, Lewis FM, Rimer BK (eds). Health Behavior and Health, CA. Education: Theory, Research and Practice, 2nd edn. Jossey-Bass, San Francisco.1997b.

12. Crosby RA, Kegler MC, DiClemente RJ. Understanding and applying, theory in health promotion practice and research. In DiClemente RJ Crosby RA Kegler MC (eds), Emerging Theories in Health Promotion Practice and Research: Strategies for Improving the Public Health. Jossey-Bass, San Francisco, CA, 2012: 1-15.

13. Rama Chandran M, Darmalingam T. health education. New Delhi: Vikas, 2 Edition.1995.

14. Green LW, Kreuter MW, Deeds SG, partridge KW. Health education planning: a diagnostic approach.1 Edition. Mayfield Dublishing Company: California. 1980.

15. Butler JT. Principles of health education and health promotion.(3th ed). Wadsworth: Belmont. 2001.

16. Green LW, Kreuter MW. CDC's Planned Approach to Community Health as an application of PRECEDE and an inspiration for PROCEED. J Health Educ 1992; 23: 140-147.

17. Chabat I, Moisan J, Gregoire JP, Milot A. Pharmacist intervention program for control of hypertension. Ann Pharmacother 2003; 37: 1186-1193.

18. Sanainasab H, Ghofranipour FA, Kazemnejad A, Khavanin A, Tavakoli R. Impact of safety traning on promoting safe behaviors of workers through the use of integrated models PRECEDE- PRPCEED with social cognitive theory and adult learning. Behbood 2008; 12: 11-25. [In Persian]

19. Hosseini Z, Moeini B, Hazavehei SMM, Aghamollai T, Moghimbeigi A. Effect of educational stress management, based on PRECEDE model, on job stress of nurses. Med J Hormozgan Uni 2011; 15: 200-208. [In Persian]

20. Svien LR, Senne SA, Rasmussen C. South Dakota accidental childhood deaths, 2000-2007: what can we do? South Dakota Medicine 2010.

21. Rezapur-Shahkolaie F, Afshari M, Moghimbeigi A, Hazavehei SMM. Home-related injuries among underfive-year children and mothers' care regarding injury prevention in rural areas. Int J Inj Contr Saf Promot 2017; 24: 354-362.

22. Sethi D, Habibula S, Mcgee K, Peden M, Bennett S, Hyder A, et al. Guidelines for conducting community surveys on injuries and violence. World Health Organization Geneva. 2004.
23. Alteneder RR, Price JH, Telljohann SK, Didion J, Locher A. Using the PRECEDE model to determine junior high school students' knowledge, attitudes, and beliefs about AIDS. J Sch Health 1992; 62: 464-470.

24. Chiang LC, Huang JL, Lu CM. Educational diagnosis of self-management behaviors of parents with asthmatic children by triangulation based on PRECEDEPROCEED model in Taiwan. Patient Educ Couns 2003; 49: 19-25.

25. Mashreky SR, Rahman A, Chowdhury SM, et al. Perceptions of rural people about childhood burns and their prevention: a basis for developing a childhood burn prevention programme in Bangladesh. Public Health 2009; 123: 568-572.

26. Abdalla S; Sudan Household Health Survey 2010 National Management Team. Patterns of vulnerability to non-fatal injuries in Sudan: Initial evidence from a national cross-sectional survey. Inj Prev 2014; 20: 310-316.

27. Morrongielo BA, Corbett M, Lasenby J, Johnston N, McCourt M. Factors influencing young children's risk of unintentional injury: Parenting style and strategies for teaching about home safety. J Appl Dev Psychol 2006; 27: 560-570.

28. Salinero-Fort MA, Carrillo-de Santa Pau E, ArrietaBlanco FJ, et al. Effectiveness of PRECEDE model for health education on changes and level of control of HbAlc, blood pressure, lipids, and body mass index in patients with type 2 diabetes mellitus. BMC Public Health 2011; 11: 267.

29. Rezapur-Shahkolai F, Naghavi M, Shokouhi M, Laflamme L. The prevention and control of road traffic injuries in rural communities: input from community health workers in rural Twiserkan, Iran. Inj Prev 2010; 16 (Suppl 1): A118.

30. Shokouhi M, Rezapur-Shahkolai F, Naghavi M, Laflamme L. Fall safety promotion in rural communities. Input from injury data and community health workers in Twiserkan, Iran. Inj Prev 2010; 16 (Suppl 1): A262-A263.

31. Ribas Rde C Jr, Tymchuk AJ, Ribas AF. Brazilian mothers' knowledge about home dangers and safety precautions: An initial evaluation. Soc Sci Med 2006; 63: 1879-1888.

32. Jetten P, Chamania S, van Tulder M. Evaluation of a community-based prevention program for domestic burns of young children in India. Burns 2011; 37: 139-144. 